\title{
Real Estate Prices Affecting Factors based on Grey Relational Analysis
}

\author{
Lei Jiang ${ }^{\mathrm{a}}$, Yunli Gao ${ }^{\mathrm{b}}$ and Li Chen ${ }^{\mathrm{c}}$ \\ School of Civil Engineering, Dalian Nationalities University, Dalian 116600, China; \\ ajianglei0310@163.com, byunligao@163.com, c1196915047@qq.com
}

Keywords: Grey relational analysis, Real estate price, Affecting factor

\begin{abstract}
This paper selected seven factors which affect the housing price from macro economic environment, market demand, and living stands of people, and then analyzed the influence of key factors on the price. Based on gray correlation analysis model, the case study is employed in Dalian, and the the importance degree of factors affecting housing prices and the rank can be calculated. It can be concluded that the importance order of factors affecting the real estate prices in Dalian are: per capita consumption expenditure, Resident per capita disposable income, Land transaction price index, the area of real estate sales, the consumer price index, per capita GDP, GDP. This paper can provide a scientific basis for engineering project decisions, market planning and feasibility studies.
\end{abstract}

\section{Introduction}

In recent years, the real estate industry develops fast and changes quickly, the real estate price in some cities was too high for people. Although the state has issued a series of policy such as "The five policies of the state" control measures [1], local control measures as "Beijing eight policies" and "Shanghai six policies" are introduced accordingly, but the real estate price does not seem to stop the pace of rising. Real estate price is always a focus that many scholars payed attention to, and most of the study used statistics method to establish the model concerning with housing price. Grey Relational Analysis provide a novel way to analysis the changing real estate price.

In 1982, Professor Julong Deng proposed grey theory. The theory focus on uncertainty system of "partial information is known, and partial information is unknown", and is fit for "small sample", "poor information". It mainly uses the "partial" information known to generate, develop and extract valuable information to achieve operational behavior of the system, the correct description and effective monitoring of the evolution [2]. In the process of system development, if the changing trend of two factors is consistent, that is a high degree of synchronous changing, indicating the two factors have high correlative degree, on the other hand, the two factors have low correlative degree [3].

The application of Grey relational analysis in the real estate field obtains good results, which is mainly used in house price prediction, demand forecasting, the real estate investment analysis, forecasting and so on [4]. While more and more research appearing in this area, most of them point out what in the end affect the price only, but few of them analysis the importance degree of various factors [5]. This paper selected seven factors from economic, market, and living stands of people that affect housing price, took the city of Dalian for example, applied gray relational analysis to calculate the relative importance of each factor and analysis the reason for it.

\section{Select the main factors affecting the price of housing}

There are many factors that affect housing prices, but mainly are economic factors, market factors ,policy factors and living stands of people [6]. After review of references, this paper selected seven major factors to study as follows: GDP, per capita GDP, residents per capita disposable income, per capita consumption expenditure, consumer price index, the area of real estate sales and land transaction price index, as shown in table 1. We chose the data form 2007 to 2012 from "Dalian Yearbook" [7] and the basic data are shown in table 2. 


\section{Grey relational analysis model}

Determine analysis of sequence. Table 2 have been given reference sequence $\mathrm{X} 0$ of system, the average selling price of commercial housing. Comparative sequence is the Influencing factors of Dalian real estate prices $\mathrm{Xi}, \mathrm{i}=1,2 \ldots \ldots 7$. Therefore, Table 2 constitute a sequence matrix.

Non-dimensional treatment. In general, we often use the mean or initialization to deal with sequence matrix with dimensionless. In most cases, in order to a more stable social and economic systems we usually use the initialization conversion. The calculation formula is as follows [8]:

$$
X_{i}(k)=\frac{X_{i}(k)}{X_{0}(1)}, i=1,2, \cdots, n ; k=1,2, \cdots, m
$$

Dimensionless matrix obtained is shown in table 3.

Table 1 . The indicators of house price

\begin{tabular}{ccc}
\hline Indicators & Mean of factors & Unit \\
\hline X0 & House price & Yuan $/ \mathrm{m}^{2}$ \\
X1 & GDP & hundred million yuan \\
X2 & per capita GDP & yuan \\
X3 & residents per capita disposable income & yuan \\
X4 & per capita consumption expenditure & yuan \\
X5 & consumer price index & - \\
X6 & the area of real estate sales & ten thousand $\mathrm{m}^{2}$ \\
X7 & land transaction price index & - \\
\hline
\end{tabular}

Table 2.Basic data in dalian from 2007 to 2012

\begin{tabular}{ccccccc}
\hline Indicators & 2007 & 2008 & 2009 & 2010 & 2011 & 2012 \\
Year & & & & & & \\
\hline X0 & 5567 & 5886 & 6249 & 7044 & 8051 & 8004 \\
X1 & 3131 & 3858.2 & 4417.7 & 5158.1 & 6150.1 & 7002.8 \\
X2 & 51624 & 63198 & 71833 & 77096 & 91287 & 102216 \\
X3 & 15109 & 17500 & 19014 & 21293 & 24276 & 27539 \\
X4 & 12135 & 14101 & 15330 & 16580 & 18846 & 20417 \\
X5 & 104 & 105.4 & 100.2 & 102.7 & 105.4 & 103.4 \\
X6 & 828.2 & 730.3 & 1152.7 & 1215.3 & 910.2 & 1076.4 \\
X7 & 103.9 & 104.8 & 105.7 & 101.9 & 102.7 & 109.6 \\
\hline
\end{tabular}

Table 3 Normalized values

\begin{tabular}{lcccccc}
\hline & 2007 & 2008 & 2009 & 2010 & 2011 & 2012 \\
\hline $\mathrm{X} 0$ & 1 & 1.0573 & 1.1225 & 1.2653 & 1.4462 & 1.4378 \\
$\mathrm{X} 1$ & 1 & 1.2323 & 1.4110 & 1.6474 & 1.9643 & 2.2366 \\
$\mathrm{X} 2$ & 1 & 1.2242 & 1.3915 & 1.4934 & 1.7683 & 1.9800 \\
$\mathrm{X} 3$ & 1 & 1.1583 & 1.2585 & 1.4093 & 1.6067 & 1.8227 \\
$\mathrm{X} 4$ & 1 & 1.1620 & 1.2633 & 1.3663 & 1.5530 & 1.6825 \\
$\mathrm{X} 5$ & 1 & 1.0135 & 0.9635 & 0.9875 & 1.0135 & 0.9942 \\
$\mathrm{X} 6$ & 1 & 0.8818 & 1.3918 & 1.4674 & 1.0990 & 1.2997 \\
$\mathrm{X} 7$ & 1 & 1.0087 & 1.0173 & 0.9808 & 0.9885 & 1.0549 \\
\hline
\end{tabular}




\section{Calculate the correlation degree}

First, calculate the difference sequence as follows: $z_{i j}=\left|x_{0 j}-x_{i j}\right|$. Then, calculate range, the maximum value of the range is 0.7988 and minimum value of the range is 0.0000 . After that, calculate the correlation coefficient using the formula: $\xi_{0 i}(j)=\frac{\min _{i} \min _{j} z_{i j}+\rho \max _{i} \max _{j} z_{i j}}{z_{i j}+\max _{i} \max _{j} z_{i j}}, i \in m ; j \in n$

$\rho$ is the distinguishing coefficient [9], $\rho \in(0,1)$, usually, $\rho=0.5$.

The grey relational grade for the sequence of $\mathrm{Xi}$ is calculated by averaging the grey relational coefficients as follows:

$r_{i}=\frac{1}{n} \sum_{j=1}^{m} \xi_{0 i}(j), i \in m$

The grey relational grade $\gamma \mathrm{i}$ defines the effect of comparative sequence to the tendency of reference sequence, and the comparative sequence are ordered by it.

Table 4 Grey relational coefficients and grey relational grades

\begin{tabular}{ccccccccc}
\hline & 2007 & 2008 & 2009 & 2010 & 2011 & 2012 & mean & rank \\
\hline X1 & 1.0000 & 0.6953 & 0.5806 & 0.5111 & 0.4353 & 0.3333 & 0.5926 & 7 \\
X2 & 1.0000 & 0.7053 & 0.5976 & 0.6365 & 0.5536 & 0.4242 & 0.6528 & 6 \\
X3 & 1.0000 & 0.7982 & 0.7460 & 0.7350 & 0.7133 & 0.5092 & 0.7503 & 2 \\
X4 & 1.0000 & 0.7923 & 0.7394 & 0.7982 & 0.7890 & 0.6201 & 0.7898 & 1 \\
X5 & 1.0000 & 0.9012 & 0.7153 & 0.5898 & 0.4800 & 0.4738 & 0.6933 & 5 \\
X6 & 1.0000 & 0.6947 & 0.5973 & 0.6640 & 0.5350 & 0.7431 & 0.7057 & 4 \\
X7 & 1.0000 & 0.8915 & 0.7915 & 0.5840 & 0.4660 & 0.5106 & 0.7073 & 3 \\
\hline
\end{tabular}

\section{Results and analysis}

\section{Results}

Based on the above calculate results, the importance sequence of factors affecting house prices in Dalian are: per capita consumption expenditure, resident per capita disposable income, Land transaction price index, the area of real estate sales, the consumer price index, per capita GDP, GDP.

\section{Result Analysis}

The order of factors can be seen in table 4, the top three most important factors influencing the real estate price are per capita consumption expenditure, resident per capita disposable income and land transaction price index. Where the per capita consumption expenditure on behalf of residents consumption level, reflecting the people's demand and capability of expenditure. People's needs will indirectly stimulate commodity prices, so it can affect the housing prices obviously.

Per capita disposable income reflects the income level of residents, shows housing prices and the income of residents are closely related. The increase of income represents a potential increase in purchasing power, so the economic development is also a major factor affecting the price of commercial housing.

The land transaction price index reflects the changing trend of the land cost, the correlation degree is 0.7073 , which shows the effect of the land price can effect house price in a certain degree. Real estate attached to the land, this dependence determines the impact of the land price to house prices [10]. Because of China's urban land is state-owned, if real estate developers want to get land, the only way is the state transfer, so the land price is a large part in the cost of real estate and it is staying at a high level [11]. 


\section{Conclusions}

This paper calculate and analyzes of the factors that affect housing prices in Dalian based on grey relational analysis. Results from the model point out that, the level of consumption, the level of economic development and urban land costs greatly impact real estate prices. The real estate industry covers a wide range, has a large impact on national economy. Real estate price, as one measure of the real estate industry, is suitable for the use of gray system theory. However, this indicator is only proper for Dalian in China from 2007 to 2012, with the economic development and the change of market, government policy and social environment, the real estate price would also change, and the influencing factors would also change. As a result, the final result of the research would be different to the description as discussed above.

\section{Acknowledgment}

This work is supported by the Central Universities Independent Research Fund, China(No.DC201502040302).

\section{References}

[1] Chen Gang,Shao Wei, "The five policies of the state" can reduce the high housing prices? Economic problems,No.5,2013,pp.20.

[2] Yuxia Wang,Customer Satisfaction promotion strategy of supermarket based on gray correlation analysis ,Journal of JiLin business and technology college,Vol.30,No.1 Feb. 2014,pp.72.

[3] Chaoguang Tang,Grey correlation analysis of factors affecting rates, Social Forum, 2013,pp.183.

[4] Cuiyou Yao,Analysis of the factors affecting housing price in Beijing based on grey relational analysis,Journal of Capital University of Economics and Business,No.1,2008,pp.80

[5] Lili Zhao, Jiwen Jiao,Grey relational analysis on factors affecting housing price, Statistics and Decision Making, Vol 23, 2007,pp.74.

[6] Houxia Huang,Liying Hou,Summary of factors influencing housing prices,China real estate (semimonthly Academic Edition), No.7,2011,pp. 39- 43.

[7] Statistical yearbook of Dalian.

[8] Xiu'e Yuan, Dongmei Wei, The Price Factor of BaoDing Real Estate Evaluation Based on Grey Correlation Analysis, The fourth international conference on information,communication and education application ,2013,pp.309.

[9] Xu Teng,The analysis of the influence factors on housing prices in AnHui Province which is based on the grey correlative degree,Science technology and industry ,Vol.12 Dec.2012,pp.66.

[10] Hu Gang, Explore the economic development policy of real estate,Technology and economy market,No.5,2014,pp.136.

[11] Bifeng Ye, The principle of equal compensation for land expropriation in urbanization,Chinese Law,No.3,2014, pp.126-127. 